\title{
Liquid-Solid Hybrid Resonance Method for Investigating Acoustic Properties of Magmas
}

\author{
Akira Yoneda* \\ Dept. of Earth and Planet. Sci., Nagoya University \\ Nagoya 464-01, Japan
}

\begin{abstract}
I propose a new experimental method to measure acoustic properties of liquid and soft material. The resonance method utilizes eigenvibration modes to determine elastic properties of a sample with given density, size, and shape $[1,2,3]$; it has been used for many solid samples, even at high temperatures up to $\sim 1800 \mathrm{~K}$ [4]. A new of idea vibrating a liquid sample together with its solid container enables us to apply the resonance method even to liquid, or extremely soft material. For that experimental analysis, I have developed the xyzr algorithm which enables us to calculate eigenfrequency of bored and laminated objects. I have conducted preliminary experiments on soft plastic (Juracon) accommodated in an aluminum tube and silicone rubber in a copper tube. I succeeded in identifying several peaks on that composite systems, and recalculated $\mathrm{v}_{\mathrm{s}}=950$ $\mathrm{m} / \mathrm{s}$ for Juracon and $v_{\mathrm{s}}=220 \mathrm{~m} / \mathrm{s}$ for silicone rubber, respectively. The resonance method enables us even to determine $\mathrm{Q}$-value from peak width. Those $\mathrm{Q}$ is 59 for Juracon and 580 for silicone rubber, respectively at around $70 \mathrm{kHz}$.

[Keywords: elasticity, anelasticity, eigenvibration, plastic, magma]
\end{abstract}

\section{The resonance method}

Figure 1 summarizes the idea of the resonance experiments. One transducer is used for exciting vibration of a specimen, and the other detects the amplitude of the sample vibration. The amplitude of sample vibration is monitored as a function of exciting frequency. In the liquid-solid hybrid resonance method, the specimen is a composite system.

Figure 2 shows an example of ultrasonic spectroscopy on a aluminum tube with/without Juracon; you can see significant effect of the inner material. We can determine elastic properties of the inner material from the hybrid eigenvibration frequencies, as long as a numerical calculation algorithm is available for the eigenfrequencies. I developed the xyzr algorithm for analyzing eigenvibration of such a composite system [5].

\section{The xyzr algorithm for eigenvibration analysis}

The eigenvibration problem has been analyzed by means of the Rayleigh-Ritz method based on Hamilton's principle. Holland [6] solved the eigenvibration problem of a cube with cubic crystallographic symmetry by using trigonometric functions as the base functions. Demarest [7] improved convergency of the same problem by introducing Legendre polynomials as the base functions. Ohno [1] expanded Demarest's solution to a parallelepiped rectangle with orthorhombic crystallographic symmetry. Senoo and Nishimura [8] obtained numerical solutions for a cylinder by combining the Rayleigh-Ritz method and the finite element method by using the base functions of Legendre polynomials as well. However further progress has not been achieved yet in this analyzing scheme owing to manipulate complicated Legendre polynomials.

*Present address: Inst. for Study of the Earth's Interior, Okayama Univ., Misasa, Tottori 682, Japan

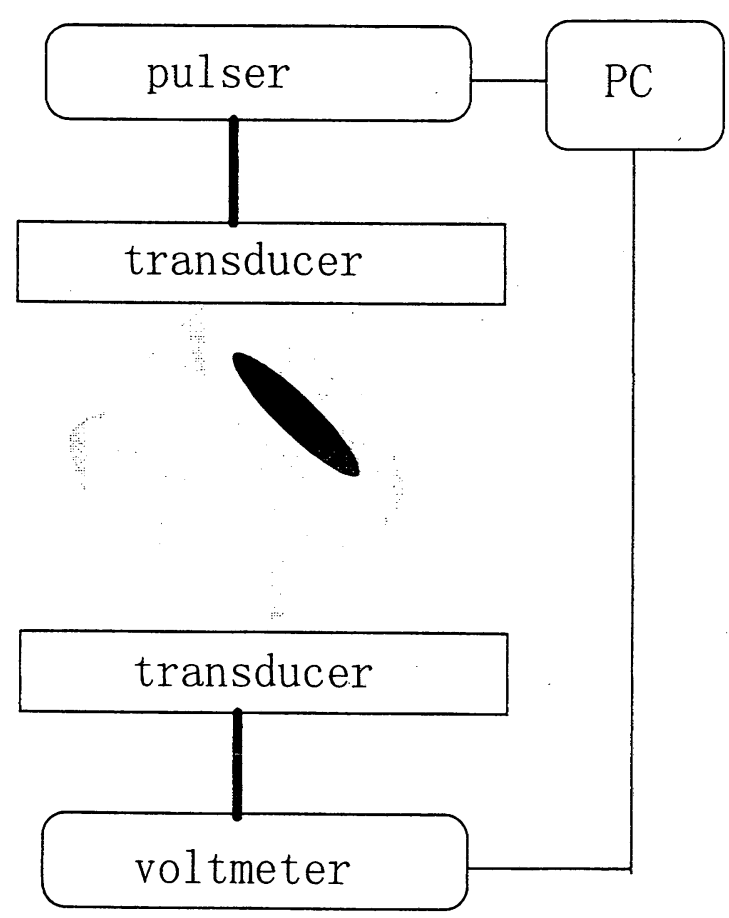

Fig. 1. Schematic view of the resonance experiments. Note that the sample is a bored or composite cylinder. 

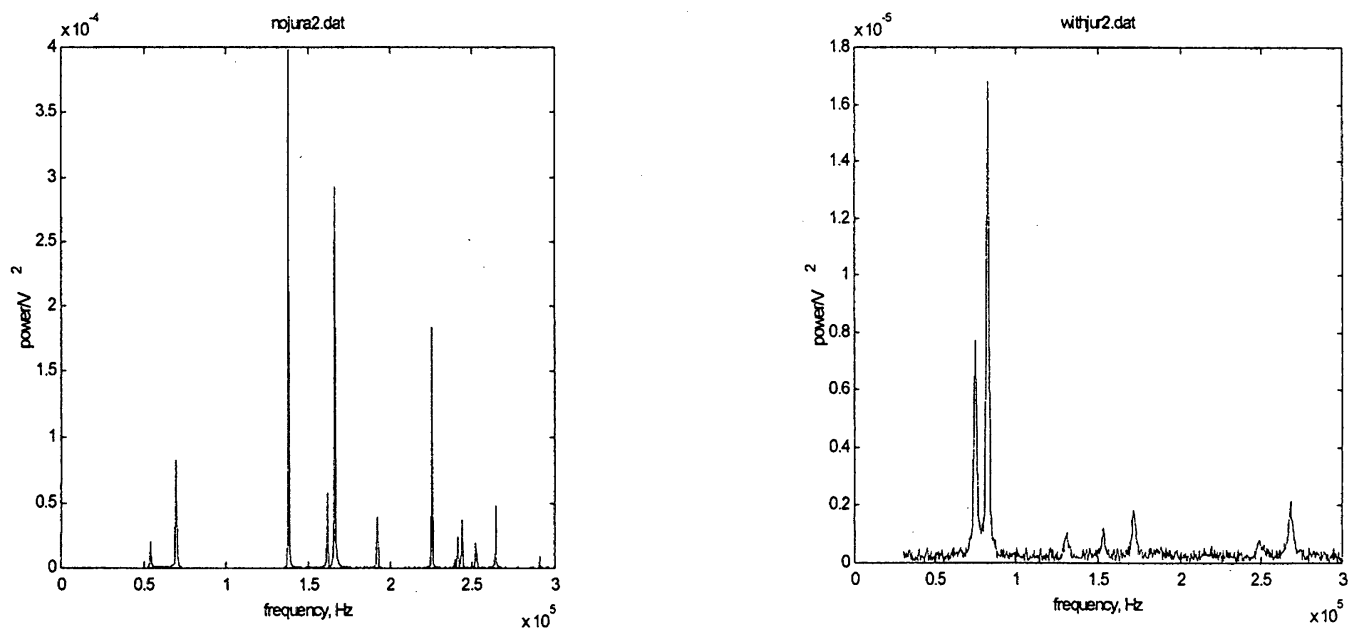

Fig. 2 Left: ultrasonic spectroscopy of the empty aluminum tube. Right: after filling with Juracon.
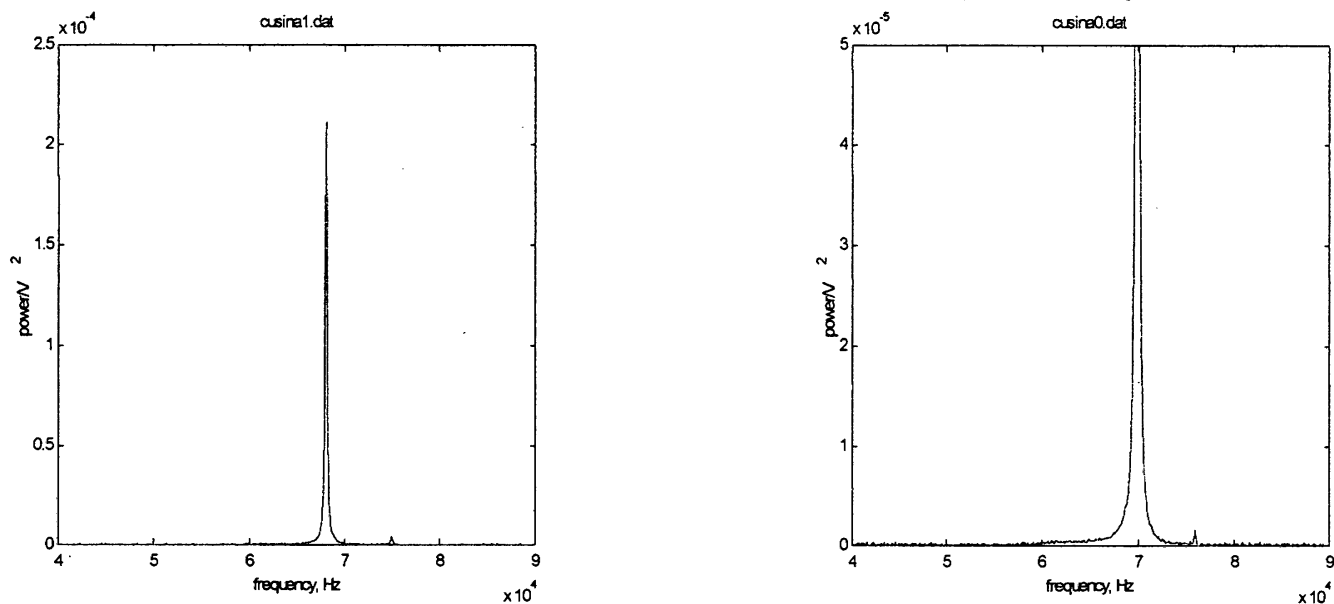

Fig. 3. Left: ultrasonic spectroscopy of the empty copper tube. Right: after filling with silicone rubber. Unlike the above figure, this shows only the lowest two modes.
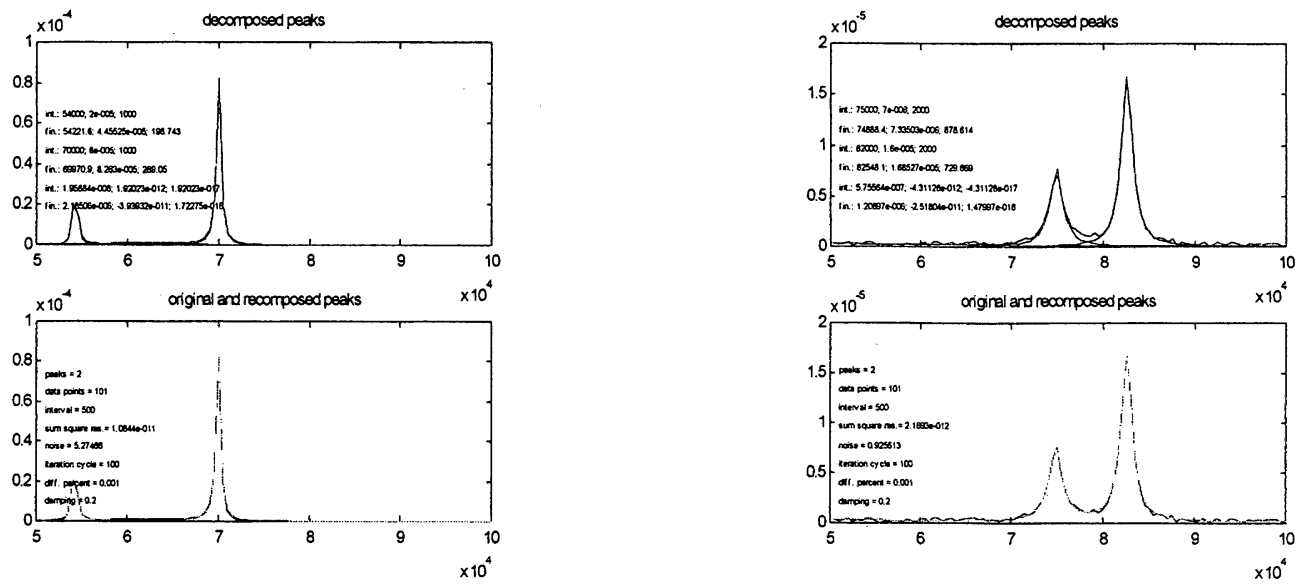

Fig. 4. Examples of curve fitting: Left: empty aluminum tube. Right: the aluminum tube with Juracon. 
Table 1. Observed and recalculated frequencies for the aluminum tube (outer diameter $9.95 \mathrm{~mm}$; inner diameter $6.7 \mathrm{~mm}$; length $6.7 \mathrm{~mm}$ ) filled with/without Juracon. Densities of aluminum and the plastic are, $2690 \mathrm{~kg} / \mathrm{m}^{3}$ and $1424 \mathrm{~kg} / \mathrm{m}^{3}$, respectively. $P$ and $S$ wave velocities of aluminum are $5167 \mathrm{~m} / \mathrm{s}$ and $3137 \mathrm{~m} / \mathrm{s}$, respectively, from the empty aluminum tube. The $S$ wave velocity of Juracon is determined at $949.9 \mathrm{~m} / \mathrm{s}$ under the constraint of $v_{\mathrm{p}}=2336 \mathrm{~m} / \mathrm{s}$, which is determined by the pulse transmission technique at $5 \mathrm{MHz}$. Note that the measurements were done at every $0.1 \mathrm{kHz}$, and those observed frequencies below are the summit value of each peak.

\begin{tabular}{|c|c|c|c|}
\hline \multicolumn{2}{|c|}{ empty tube } & \multicolumn{2}{c|}{ filled tube } \\
\hline $\mathrm{f}_{\text {obs, }, \mathrm{kHz}}$ & $\mathrm{f}_{\mathrm{cal},}, \mathrm{kHz}$ & $\mathrm{f}_{\text {obs, }}, \mathrm{kHz}$ & $\mathrm{f}_{\text {cal },}, \mathrm{kHz}$ \\
\hline 53.9 & 53.5 & 74.7 & 84.6 \\
\hline 69.5 & 70.4 & 82.2 & 132.4 \\
\hline 137.6 & 139.0 & 130.7 & 151.9 \\
\hline 161.2 & 161.6 & 152.6 & 171.7 \\
\hline 165.9 & 164.3 & 171.6 & \\
\hline 191.8 & 187.3 & & \\
\hline 225.3 & 224.0 & & \\
\hline 241.4 & 241.7 & & \\
\hline 243.8 & 246.0 & & \\
\hline 251.8 & 253.4 & & \\
\hline 264.5 & 268.1 & & \\
\hline 290.5 & 287.4 & & \\
\hline
\end{tabular}

Table 2. Characteristics of some selected modes for the copper tube (outer diameter $10.0 \mathrm{~mm}$; inner diameter $5.0 \mathrm{~mm}$; length $7.0 \mathrm{~mm}$ ) filled with silicone rubber. Densities of the copper and silicone rubber are $8487 \mathrm{~kg} / \mathrm{m}^{3}$ and $1102 \mathrm{~kg} / \mathrm{m}^{3}$, respectively. In the calculation the following velocities are used; $v_{\mathrm{p}}$ and $v_{\mathrm{s}}$ of copper are 4633 $\mathrm{m} / \mathrm{s}$ and $2183 \mathrm{~m} / \mathrm{s}$, and those of silicone $950 \mathrm{~m} / \mathrm{s}$ and $220 \mathrm{~m} / \mathrm{s}$, respectively. Note that these velocities except for $v_{\mathrm{s}}$ of silicone rubber are measured value by means of the pulse transmission method at $5 \mathrm{MHz} ; 220 \mathrm{~m} / \mathrm{s}$ is the recalculated value for $v_{\mathrm{s}}$ of silicone rubber from the observed peaks.

\begin{tabular}{|l|l|l|l|l|l|}
\hline Mode & $\mathrm{f}_{\mathrm{cal}}, \mathrm{kHz}$ & $\frac{\partial f}{\partial v_{p o}}$ & $\frac{\partial f}{\partial v_{s o}}$ & $\frac{\partial f}{\partial v_{p i}}$ & $\frac{\partial f}{\partial \nu_{s i}}$ \\
\hline$\# 1$ & & $0.57 \mathrm{E}-5$ & $0.17 \mathrm{E}-1$ & $0.38 \mathrm{E}-5$ & $0.24 \mathrm{E}+3$ \\
\hline$\# 2$ & 53.773 & $0.15 \mathrm{E}+1$ & $0.17 \mathrm{E}+2$ & $0.46 \mathrm{E} 0$ & $0.10 \mathrm{E}+3$ \\
\hline$\# 3$ & 69.337 & $0.78 \mathrm{E} 0$ & $0.84 \mathrm{E}+1$ & $0.46 \mathrm{E} 0$ & $0.21 \mathrm{E}+3$ \\
\hline$\# 4$ & 71.786 & $0.41 \mathrm{E} 0$ & $0.11 \mathrm{E}+2$ & $0.69 \mathrm{E} 0$ & $0.20 \mathrm{E}+3$ \\
\hline$\# 5$ & 75.307 & $0.71 \mathrm{E} 0$ & $0.19 \mathrm{E}+2$ & $0.87 \mathrm{E}-1$ & $0.14 \mathrm{E}+3$ \\
\hline
\end{tabular}

Table 3. Summary of absorption data. C: empty copper tube; S: silicone-filled copper tube; A: empty aluminum tube; $\mathrm{J}$ : Juracon-filled aluminum tube. \#1 mode is a deformation mode, and \#2 torsion one. Values in parentheses of $\# \mathrm{~S}$ and $\# \mathrm{~J}$ modes are the fraction of vibrating energy in the inner material. Note that those modes are free from dilatation and contraction; those $Q$ are for shear vibration.

\begin{tabular}{|l|l|l|l|l|l|}
\hline Mode & $\begin{array}{l}\mathrm{f}_{\text {obs, }} \\
\mathrm{kHz}\end{array}$ & $\begin{array}{l}\mathrm{Df}_{\text {obs, }}, \\
\mathrm{kHz}\end{array}$ & mode $\mathrm{Q}^{-1}$ & intrinsic $\mathrm{Q}^{-1}$ & $\mathrm{Q}$ \\
\hline \#C1 & $69.899(1)$ & $0.094(1)$ & $1.34 \mathrm{E}-3$ & $1.34 \mathrm{E}-3$ & 746 \\
\hline \#C2 & $75.904(1)$ & $0.107(2)$ & $1.41 \mathrm{E}-3$ & $1.41 \mathrm{E}-3$ & 709 \\
\hline \#S1(53.7\%) & $68.055(1)$ & $0.106(1)$ & $1.56 \mathrm{E}-3$ & $1.75 \mathrm{E}-3$ & 572 \\
\hline \#S2(27.6\%) & $74.983(1)$ & $0.112(2)$ & $1.49 \mathrm{E}-3$ & $1.72 \mathrm{E}-3$ & 583 \\
\hline \#A1 & $54.219(1)$ & $0.22(1)$ & $4.0 \mathrm{E}-3$ & $4.0 \mathrm{E}-3$ & 250 \\
\hline \#A2 & $69.971(1)$ & $0.29(1)$ & $4.1 \mathrm{E}-3$ & $4.1 \mathrm{E}-3$ & 240 \\
\hline \#J1(61.9\%) & $74.891(2)$ & $0.90(2)$ & $1.2 \mathrm{E}-2$ & $1.7 \mathrm{E}-2$ & 59 \\
\hline \#J2(38.0\%) & $82.548(2)$ & $0.74(2)$ & $9.0 \mathrm{E}-3$ & $1.7 \mathrm{E}-2$ & 59 \\
\hline
\end{tabular}


The xyz algorithm by Visscher et. al. [9] gave us a breakthrough in this field. They showed that simple power functions in the Cartesian coordinates can be used for the base functions. In the xyz algorithm, the displacement in the $i$-th direction $u_{i}(x, y, z)$ is expanded as

$$
\begin{gathered}
u_{i}=\sum a_{\lambda_{i}} \varphi_{\lambda_{i}} \\
\varphi_{\lambda_{i}}=x^{l} y^{m} z^{n} \vec{e}_{i}
\end{gathered}
$$

where $\bar{e}_{i}(i=1,2,3)$ is a directional unit vector in the Cartesian coordinate. The integers of $l, m, n$ are limited by an integer $N$ as

$$
l+m+n \leq N
$$

The xyz algorithm provides us with easy analysis of eigenvibration of an object even with internal inhomogeneity, elastic anisotropy, and irregular shape. Its wide versatility inspired me to devise a new experimental technique to investigate rheological properties of liquid and soft material by measuring eigenvibration frequencies of a container filled with the target material. However, I found that the xyz algorithm is not so accurate for an object with inner and outer interfaces such as a tube and a spherical shell.

Thus I developed the xyzr algorithm which uses the following two types of base functions $\varphi_{\lambda}{ }^{(1)}$, and $\varphi_{\lambda}{ }^{(2)}$

$$
\begin{array}{ll}
\varphi_{\lambda}{ }^{(1)}=x^{l} y^{m} z^{n} \vec{e}_{i}, & r<r_{i} \\
\varphi_{\lambda}{ }^{(1)}=\frac{x^{l} y^{m} z^{n} r_{i}^{k}}{r^{k}} \vec{e}_{i} \quad r_{i}<r<r_{o} \\
\varphi_{\lambda}{ }^{(2)}=\frac{x^{l} y^{m} z^{n} r^{j}}{r_{i}^{j}} \vec{e}_{i} \quad r<r_{i} \\
\varphi_{\lambda}{ }^{(2)}=\frac{x^{l} y^{m} z^{n} r_{i}^{k}}{r^{k}} \vec{e}_{i} \quad r_{i}<r<r_{o}
\end{array}
$$

where displacement continuity at $r=r_{i}$ are realized by introducing $r_{\mathrm{i}}^{\mathrm{k}}$ or $r_{\mathrm{i}}^{\mathrm{j}}$ into Eqs. (4b) and (5b). By using these base functions, we can calculate accurate frequencies of the composite specimens [5].

\section{Preliminary experiments}

Two preliminary experiments are conducted. One is an aluminum tube with Juracon, and the other a copper tube with silicone rubber. Table 1 summarizes the peaks used for determining the velocities of the aluminum and Juracon. For aluminum, I recalculated $v_{\mathrm{p}}=5167 \mathrm{~m} / \mathrm{s}$ and $v_{\mathrm{s}}=3137$. By fixing those velocities for aluminum, I recalculated $v_{\mathrm{s}}=949.9 \mathrm{~m} / \mathrm{s}$ for Juracon under the constraint of $v_{\mathrm{p}}=2336 \mathrm{~m} / \mathrm{s}$ of a roughly measured value in the pulse transmission method. For determining $v_{p}$ of Juracon in the resonance method, note that we have to identify higher frequency modes which are sensitive to $v_{\mathrm{p}}$. Those velocities, from resonance peaks, are consistent with the ultrasonic pulse transmission measurements at $5 \mathrm{MHz}$.

Similar experiments were conducted on a composite system of a copper tube. In this system, we had difficulty in identifying modes; Table 2 shows peak information for some selected modes, and Fig. 3 shows experimental results. I identified the two observed peaks as \#2 and \#5 in Table 2, because they have larger vibration energy in the outer region than others. The similar analysis as above gives us $v_{s}=220 \mathrm{~m} / \mathrm{s}$ for silicone rubber. Note that it was not able to be measured by the conventional pulse transmission method.

Another topic is $\mathrm{Q}$ values. We can derive acoustic absorption of the vibration from peak width. I summarize peak information and $Q$ values are in Table 3. The curve fitting analysis is shown in Fig. 4. Note that every \#1 peak is the simplest deformation mode, and \#2 is torsional mode along the z-axis. We recognize that $Q$ values are well determined for every material investigated as low as several $10 \mathrm{kHz}$ range.

\section{Conclusion}

The geophysical target is to investigate the acoustic properties of magmas by means of the present technique. Magmas are expected to have comparable velocities with soft plastic investigated here. Therefore the present results are enough to convince us of developing the present resonance method for the geophysical goal, as long as magmas can be accommodated in a solid container. Thus, I am devising the semi-spherical shell container instead of the cylindrical container as the next stage of the work.

\section{References}

[1] I. Ohno, J. Phys. Earth, 24, 355 (1976)

[2] Y. Sumino, J. Phys. Earth, 27, 209 (1979)

[3] J. Maynard, Pbysics Today, 49, 26 (1996).

[4] T. Goto and O. L. Anderson, J. Geophys. Res., 94, 7588(1989)

[5] A. Yoneda, submitted to J. Acoust. Soc. Am.

[6]R. Holland, J. Acoust. Soc. Am., 43, 988 (1968).

[7]H. H. Demarest, Jr., J. Acoust. Soc. Am., 49, 768 (1971).

[8]M. Senoo and T. Nishimura, Bull. Jpn. Soc. Mech. Eng., 27, 2339 (1984).

[9]W. M. Visscher, A. Migliori, T. M. Bell, and R. A. Reinert, J. Acoust. Soc. Am., 90, 2154 (1991). 